\title{
Investigating the Preparation Conditions on Superconducting Properties of $\mathrm{Bi}_{2-x} \mathrm{Li}_{\mathrm{X}} \mathrm{Pb}_{0.3} \mathrm{Sr}_{2} \mathrm{Ca}_{2} \mathrm{Cu}_{3} \mathrm{O}_{10+\delta}$
}

\author{
Muna Musa Abbas, Saad Frhan Oboudi, Nadein Qahtan Raoof \\ Physics Department, College of Science, University of Baghdad, Baghdad, Iraq \\ Email: muna moussa@yahoomail.com
}

Received 14 February 2015; accepted 6 April 2015; published 8 April 2015

Copyright $(\subset 2015$ by authors and Scientific Research Publishing Inc.

This work is licensed under the Creative Commons Attribution International License (CC BY). http://creativecommons.org/licenses/by/4.0/

cc) (i) Open Access

\begin{abstract}
One and multi-step solid state reaction methods were used to prepare a high temperature superconductor with a nominal composition $\mathrm{Bi}_{2-x} \mathrm{Li}_{x} \mathrm{~Pb}_{0.3} \mathrm{Sr}_{2} \mathrm{Ca}_{2} \mathrm{Cu}_{3} \mathrm{O}_{10+\delta}$ for $(0 \leq \mathrm{x} \leq 0.5)$. The effect of preparation conditions and substituting $\mathrm{Li}$ on $\mathrm{Bi}$ sites had been investigated by the use of $\mathrm{X}$-ray diffraction, resistance measurements and oxygen content to obtain the optimum conditions for formation and stabilization of the 2223-phase. It has been found that intermediate grinding will force to convert and accelerate the formation rate of the 2223-phase. The morphological analyses were carried out by SEM. The results showed that the multi-step technique was appropriate to prepare the composition $\mathrm{Bi}_{2-\mathrm{x}} \mathrm{Li}_{\mathrm{X}} \mathrm{Pb}_{0.3} \mathrm{Sr}_{2} \mathrm{Ca}_{2} \mathrm{Cu}_{3} \mathrm{O}_{10+\delta}$. $\mathrm{X}$-ray diffraction analysis showed two phases: high- $\mathrm{T}_{C}$ phase 2223 and low- $\mathrm{T}_{C}$ phase 2212 with orthorhombic structure for all samples. However, the optimum concentration was found for 0.3 which improved the microstructure and had the highest $T_{C}$ value $130 \mathrm{~K}$ for the highest value of oxygen content.
\end{abstract}

\section{Keywords}

Bi-2223 Superconductor, Li Substitution, Sintering Temperature, Multi-Step Methods

\section{Introduction}

High- $\mathrm{T}_{\mathrm{C}}$ superconductors comprise a collection of tiny, randomly oriented anisotropic grains which are connected to each other by a system of so called "weak links" or "matrix" and other impurity phases and defects [1]. Therefore, the orientation of the grains in the polycrystalline microstructure must be along a certain direction which is often produced textured grain alignment and causes microstructure modifications, enhancing flux pinning, and that increases the current carrying capacities. It is well established that the improvement of preparation 
process of high- $\mathrm{T}_{\mathrm{C}}$ superconductor and its conducting properties is important for practical applications.

In the Bi-2223 compound, it is difficult to align well the superconducting grains, because of the complex formation mechanism of the $\mathrm{Bi}-2223$ superconductor phase. However, the grain connectivity and the degree of texturing in the samples depend on various parameters. It has been widely proved that the starting composition, several times of intermediate grinding, sintering time and temperature have a strong influence on the (2223) phase [2].

On the other hand, the formation and stability of the 2223 phase can be modified by the addition or substitution of elements of varying ionic radii and bonding characteristics. This variation is thought to be related to the density of charge carriers in the $\mathrm{CuO}$ planes [3]. Correlation between the preparation conditions of high $\mathrm{T}_{\mathrm{C}}$ superconductors and its conducting properties is necessary to develop the practical applications. The approval of a material for application in the $\mathrm{Bi}(\mathrm{Pb}) \mathrm{SrCaCuO}$ system necessitates the ability to control the effect of different doping elements and processing parameters, on its properties.

Agostinelli and coworkers [4] pointed out that the longer annealing times resulted in more homogenous samples having a single superconducting transition to zero resistance at $108 \mathrm{~K}$.

Dey [5] studied the influences of sintering duration on the electrical resistivity and thermal conductivity of $\left(\mathrm{Bi}_{0.8} \mathrm{~Pb}_{0.2}\right)_{2} \mathrm{Sr}_{2} \mathrm{Ca}_{2} \mathrm{Cu}_{3} \mathrm{O}_{9.8+\delta}$ pellets with $0.11<\delta<0.54$ in the range of $(10-150) \mathrm{K}$. He found a gradual transformation of the 2212 phase to the 2223 phase and this transformation started within $5 \mathrm{hr}$ of sintering in air at $840^{\circ} \mathrm{C}$.

Fernando et al. [6] showed that the conventional solid state reaction method required very long heat treatment with several intermediate grinding stages in order to produce single $\mathrm{Bi} 2223$ superconducting phase.

Bilgili et al. [7] showed that $\mathrm{Bi}_{1.7} \mathrm{~Pb}_{0.3} \mathrm{Sr}_{2} \mathrm{Ca}_{2} \mathrm{Cu}_{3-\mathrm{x}} \mathrm{Li}_{\mathrm{x}} \mathrm{O}_{\mathrm{y}}$ compound with $\mathrm{x}=0.2$ exhibited a maximum critical temperature $\left(\mathrm{T}_{\mathrm{C}}=98 \mathrm{~K}\right)$, besides the samples had the highest volume fraction of the $\mathrm{Bi}-(2223)$ high- $\mathrm{T}_{\mathrm{C}}$ phase and was $81 \%$.

Muna et al. [8] found that not only the physical properties of $\mathrm{HTSc} \mathrm{Bi}_{2-\mathrm{x}} \mathrm{Cu}_{\mathrm{x}} \mathrm{Pb}_{0.3} \mathrm{Sr}_{2} \mathrm{Ca}_{2} \mathrm{Cu}_{3} \mathrm{O}_{10+\delta}$ for $\mathrm{Cu}(0.1 \leq$ $\mathrm{x} \leq 0.5$ ) depended greatly on the elemental composition, but also it was very much delicate with the details of the preparation method.

Obviously, the structure and electrical development of $\mathrm{BiPbSrCaCuO}$ systems depend on preparing condition and substitution. So the main purpose of this work is to know how they are affected by the processing variables together with the partial substitution of $\mathrm{Bi}$ by $\mathrm{Li}$, and try to find a subtle and delicate balance between composition, structure and superconducting properties for $\mathrm{Bi}_{2-\mathrm{x}} \mathrm{Li}_{\mathrm{x}} \mathrm{Pb}_{0.3} \mathrm{Sr}_{2} \mathrm{Ca}_{2} \mathrm{Cu}_{3} \mathrm{O}_{10+\delta}$ compounds.

\section{Experimental Procedures}

The samples of the system $\mathrm{Bi}_{2-\mathrm{x}} \mathrm{Li}_{\mathrm{x}} \mathrm{Pb}_{0.3} \mathrm{Sr}_{2} \mathrm{Ca}_{2} \mathrm{Cu}_{3} \mathrm{O}_{10+\delta}$ with concentration $(0 \leq \mathrm{x} \leq 0.5)$ were prepared by conventional solid-state reaction route. An appropriate weights of the starting materials, $\mathrm{Bi}_{2}\left(\mathrm{CO}_{3}\right)_{3}, \mathrm{~Pb}_{3} \mathrm{O}_{4}, \mathrm{Sr}\left(\mathrm{NO}_{3}\right)_{2}$, $\mathrm{CaO}, \mathrm{CuO}$ and $\mathrm{Li}_{2} \mathrm{CO}_{3}$ were taken with precise values. Then the powders were well mixed and grounded using agate mortar with a sufficient quantity of 2-propane to homogenize the mixture to get a fine powder. The mixture was then calcined in air at $800^{\circ} \mathrm{C}$ for $30 \mathrm{hrs}$ with intermediate re-grinding. The powder obtained reground again and pressed into disc-shaped pellets at $0.7 \mathrm{GPa}$, with thickness between $(2 \mathrm{~mm} \times 3 \mathrm{~mm})$ and $13 \mathrm{~mm}$ diameter using hydraulic pressure type (Specac).

Series of pellets were prepared with different conditions as following:

First group was sintered at $830^{\circ} \mathrm{C}$ for $140 \mathrm{hrs}$ (one step).

Second group was sintered at $840^{\circ} \mathrm{C}$ for $140 \mathrm{hrs}$ (one step).

Third group was sintered by using three steps with intermediate re-grinding and repressed for one and two steps: the samples were sintered twice at $850^{\circ} \mathrm{C}$ for $50 \mathrm{hrs}$ while in the third step the samples were sintered at $830^{\circ} \mathrm{C}$ for $40 \mathrm{hrs}$.

The structure of the prepared samples was obtained by using X-ray diffractometer type Philips with the $\mathrm{Cu}-\mathrm{K}_{\alpha}$ radiation. A computer program was used to calculate the lattice parameters, based on Cohen's last square method. The resistivity measurements were performed by the standard four-probe method.

Iodometric titration was used to access the oxygen content $\mathrm{d}$ in the samples.

Scanning electron microscopy (SEM) type (TESCAN) has been used to analyze the surface morphology and investigate the nature of the grains of $\mathrm{Bi}_{2-\mathrm{x}} \mathrm{Li}_{\mathrm{x}} \mathrm{Pb}_{0.3} \mathrm{Sr}_{2} \mathrm{Ca}_{2} \mathrm{Cu}_{3} \mathrm{O}_{10+\delta}$ with different $\mathrm{x}$. 


\section{Results and Discussion}

XRD analyses showed an orthorhombic structure of all the samples and show two main phases: high- $\mathrm{T}_{\mathrm{C}}$ phase (2223), low- $\mathrm{T}_{\mathrm{C}}$ phase (2212) with some impurities phases like $\mathrm{Sr}_{2} \mathrm{Ca}_{2} \mathrm{Cu}_{7} \mathrm{O}_{\delta}$ detected at $2 \theta$ equal to $36.8 \mathrm{O}$ as shown in Figures 1-3.

It could be seen that increase the sintering temperature causes an increase the intensity of the peaks. The most intense peak pattern of samples belongs to the high- $T_{C}$ phase which also indicates an increase in the volume fraction of the high- $\mathrm{T}_{C}$ phase [9]. Furthermore, samples of third series exhibited an enhancement of high $\mathrm{T}_{\mathrm{C}}$ (2223) peaks with increasing Li concentration. This result indicates that the substitution by Li improves the crystalline arrangement degree [10] and volume fraction of the 2223 phase.

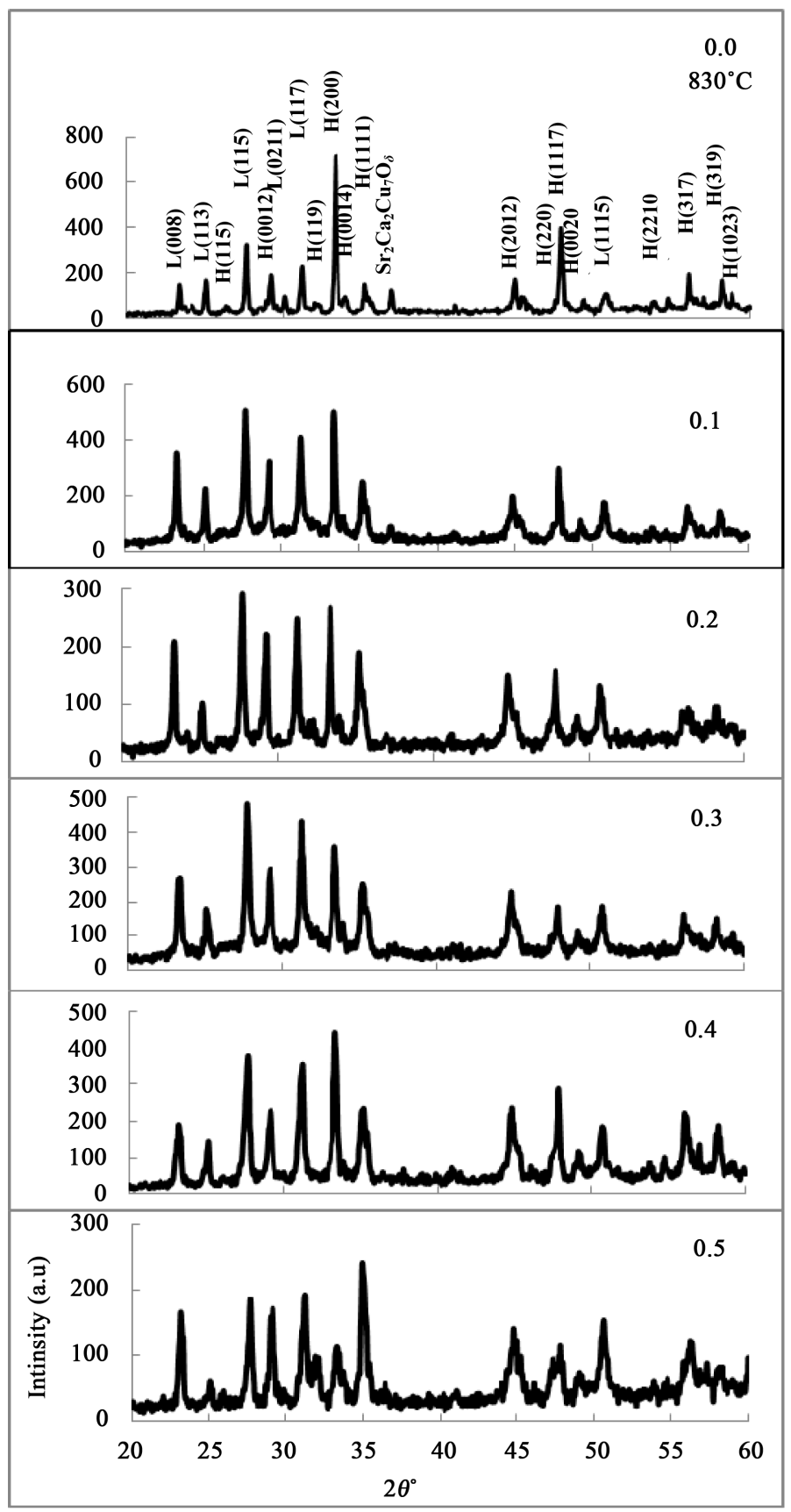

Figure 1. XRD patterns of $\mathrm{Bi}_{2-} \mathrm{Li}_{\mathrm{X}} \mathrm{Pb}_{0.3} \mathrm{Sr}_{2} \mathrm{Ca}_{2} \mathrm{Cu}_{3} \mathrm{O}_{10+\delta}$ first group. 


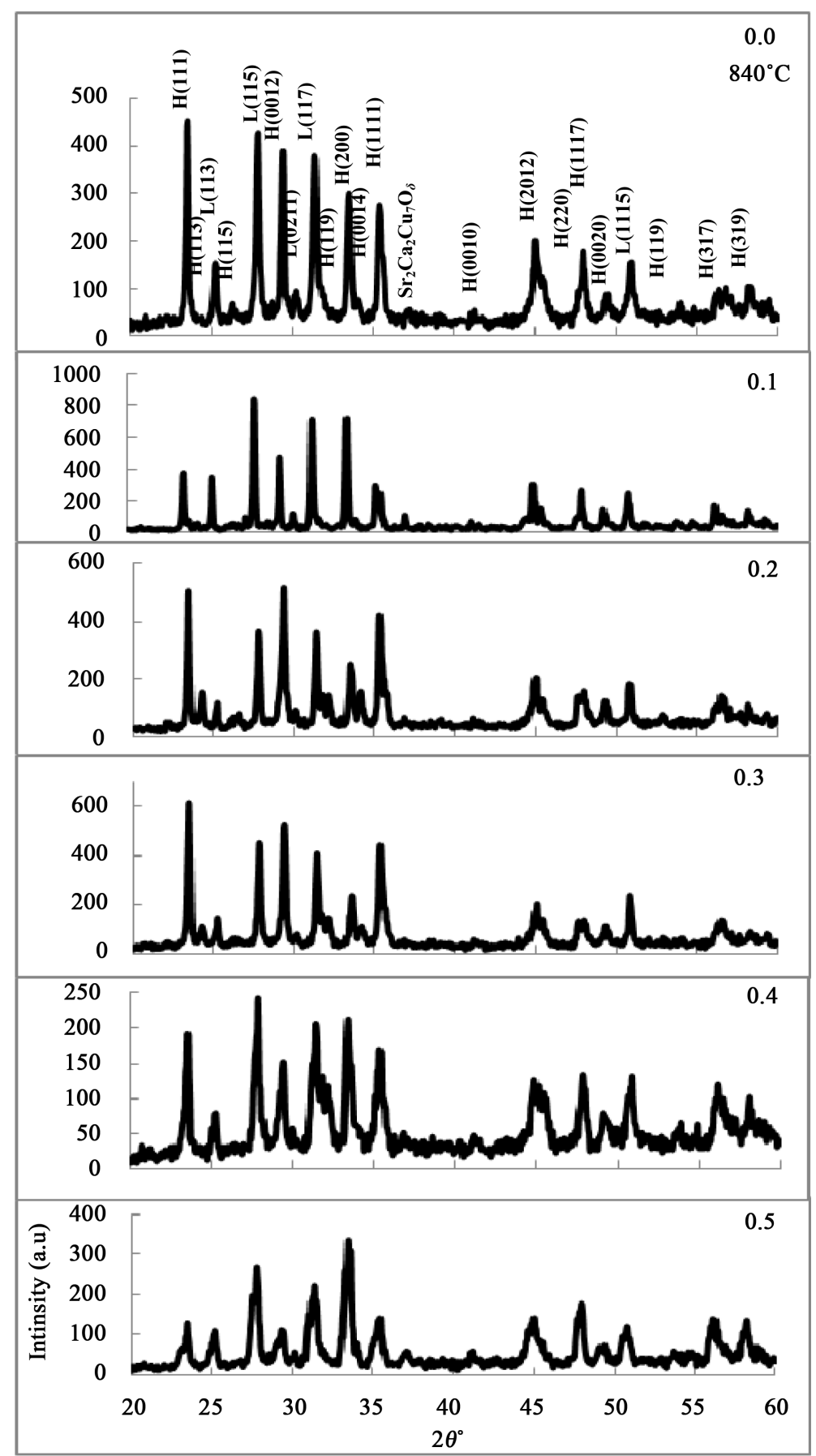

Figure 2. XRD patterns of $\mathrm{Bi}_{2-\mathrm{X}} \mathrm{Li}_{\mathrm{X}} \mathrm{Pb}_{0.3} \mathrm{Sr}_{2} \mathrm{Ca}_{2} \mathrm{Cu}_{3} \mathrm{O}_{10+\delta}$ second group.

The relative volume fractions of the $\mathrm{Bi}-2223$ and $\mathrm{Bi}-2212$ phases were estimated from the peak intensities of the same particular reflections, using the following formulas [7]:

$$
\begin{aligned}
& \operatorname{Bi}(2223) \%=\frac{\sum I(2223)}{\sum I(2223)+I(2212)} \times 100 \\
& \operatorname{Bi}-(2212) \%=\frac{\sum I(2212)}{\sum I(2223)+I(2212)} \times 100
\end{aligned}
$$




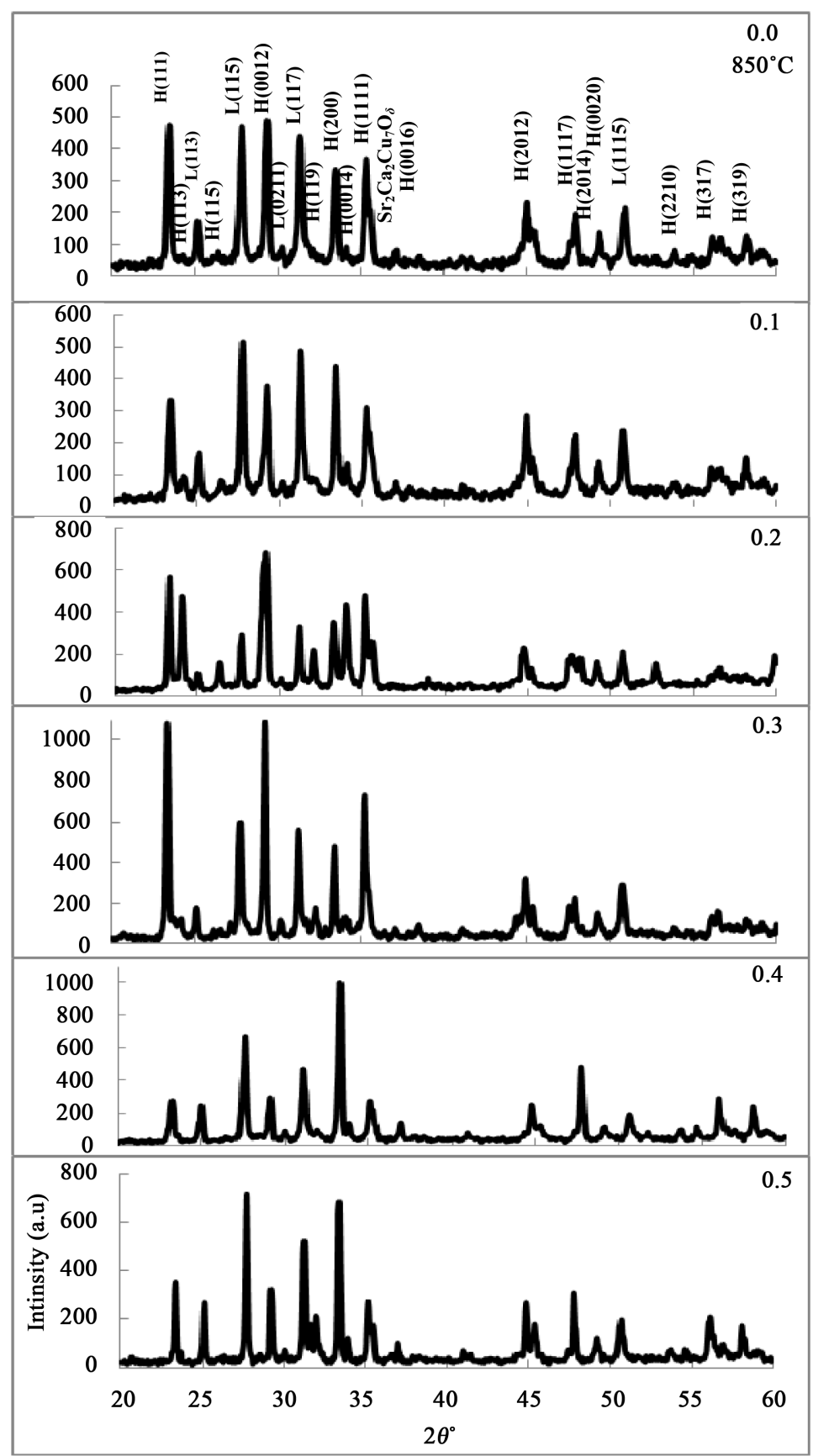

Figure 3. XRD patterns of $\mathrm{Bi}_{2-\mathrm{x}} \mathrm{Li}_{\mathrm{X}} \mathrm{Pb}_{0.3} \mathrm{Sr}_{2} \mathrm{Ca}_{2} \mathrm{Cu}_{3} \mathrm{O}_{10+\delta}$ third group.

where: $I(2223)$ and $I(2212)$ are the intensities of Bi-2223 and Bi-2212 phases respectively. The calculated relative portion of all samples is listed in Table 1. In general increasing of sintering temperature promotes the formation of high- $\mathrm{T}_{\mathrm{C}}$ phase 2223 due to improvement of the nucleation. Multi-step technique develops the superconductivity properties and necessary for growth the high- $\mathrm{T}_{\mathrm{C}}$ phase.

Samples of third series show a higher volume fraction of the 2223 phase at 0.2 for Li concentration in agreement with the previous observation by Bilgili et al. [7]. According to the model suggested by Grivel and Fliikiger [11], the (Bi,Pb)-2223 phase forms not due to a layer-by-layer intercalation in the pre-existing $(\mathrm{Bi}, \mathrm{Pb})$ 2212 grains but through a distinct nucleation and growth process. Thus, the slightly larger volume fraction of the $(\mathrm{Bi}, \mathrm{Pb})-2223$ phase present in the $\mathrm{x}=0.2$ composition might be a reason for the faster conversion rate of this 
Table 1. The lattice parameters and volume fraction of phases formed with concentration for third group.

\begin{tabular}{ccccccccc}
\hline $\mathrm{x}$ & $\mathrm{a}(\AA)$ & $\mathrm{b}(\AA)$ & $\mathrm{c}(\AA)$ & $\mathrm{c} / \mathrm{a}$ & $\mathrm{V}(\AA)^{3}$ & \multicolumn{2}{c}{ Volume fraction of phases formed (\%) } \\
\hline 0.0 & 5.306301 & 5.475111 & 37.02131 & 6.976858 & 1075.5648 & 67.49 & 32.50 \\
0.1 & 5.428631 & 5.449396 & 37.01791 & 6.819014 & 1095.0916 & 65.16 & 34.83 \\
0.2 & 5.313717 & 5.757823 & 37.14384 & 6.990180 & 1136.4322 & 73.78 & 26.21 \\
0.3 & 5.408422 & 5.473083 & 37.18519 & 6.875423 & 1100.7092 & 67.83 & 32.16 \\
0.4 & 5.446706 & 5.461773 & 37.12734 & 6.816476 & 1104.4890 & 64.34 & 35.65 \\
0.5 & 5.439214 & 5.456579 & 37.08603 & 6.81827 & 1100.6948 & 60.74 & 39.25 \\
\hline
\end{tabular}

composition. Moreover, the differences in the ionic radii of $\mathrm{Li}^{+1}, \mathrm{Bi}^{+3}$ and $\mathrm{Pb}^{+2}$ together with increasing sintering temperature [12] elongate the $\mathrm{c}$-axis then heightening of the high- $\mathrm{T}_{\mathrm{C}}$ phase furthermore.

The parameters a, b, c and V were also calculated from the XRD analysis as shown in Table 1. This table indicates that the content of $\mathrm{Bi}-2223$ increases and a change in the structural parameters was obtained with increasing $\mathrm{Li}$ concentration, this change in the lattice parameters affect the volume of the unit cell and then causes an increase in the density.

Upon Li substitution a parabolic curve for lattice parameter c is observed as illustrated in Figure 4, that is increased up to $\mathrm{x}=0.3$ then shortened towards Li concentration. This implies that the mechanism of substitution of $\mathrm{Bi}$ by $\mathrm{Li}$ is not simple. Since the ionic radius of $\mathrm{Bi}$ is greater than $\mathrm{Li}$ thus the substitution increases the distance between the $\mathrm{CuO}_{2}$ planes which leads to increase the c parameter. But increasing $\mathrm{Li}$ concentration causes reduction of the c parameter, this could be ascribed to the charge ordering phenomenon (probably induced by Li known as a pair breaker) may be a companied by change in oxygen content or oxygen ordering effects. Furthermore, the interaction between additional bands crosses the Fermi level extracts the holes from $\mathrm{CuO}$ band [13]. This attractive interaction caused the decreased of the distance between $\mathrm{CuO}_{2}$ planes. The decreased of cparameter may be caused detrimental effects on the critical temperature as will be discussed.

On other hand addition of $\mathrm{Pb}$ to the compounds may relax the modulation by influencing the charge balance, oxygen content and structural of the relevant layers [14]. From the previous considerations it is possible to state that even for the same compositions high- $\mathrm{T}_{\mathrm{C}}$ phase formation kinetics depend considerably on the preparation conditions.

The relation between volume percentages of 2223 phases with different concentrations is plotted in Figure 4. It can be inferred that the volume of 2223 phase varies systematically with c-parameter.

Measurements of electrical resistivity of the first and second group's samples are displayed in Figure 5 and Figure 6 respectively. The resistivity of most samples decreasing nearly linearly albeit to a certain limit although a complete zero-resistance hasn't been observed. Whereas samples of third group reveal a metallic behavior in the normal state and a superconducting transition to zero resistance with $T_{C}=(113,116,117,130,118$ and 113) $\mathrm{K}$ for ( $\mathrm{x}=0,0.1,0.2,0.3,0.4$, and 0.5$)$ respectively as shown in Figure 7.

It is well established that there are two types of superconducting grains, one formed by the 2223 phase and the second by the 2212 phase coupled together via some weak links and by passes the islands of the 2212 phase [15]. Once the volume fraction of 2223 phase within the sample is sufficient to make this possible, a one-step resistivity transition is observed even in the samples which contain a rather large amount of the 2221 phase.

A sharp drop of resistivity was observed for concentration $\mathrm{Li}=0$, this revealing that the sample consists of predominantly of (2223) phase; this trend is also a good evidence of the homogeneity of the (2223) phase [16] Composition with $\mathrm{x}=0.1$ shows long tail with $\mathrm{T}_{\mathrm{C}}=116 \mathrm{~K}$, the reason may existence of small amount of the secondary phase and or/fluctuation of the oxygen content.

Sample with $x=0.2$ shows two steps, reflecting the decrease of the intergrain transition. It is possible that the both superconducting phases exist within one grain in such a way that the low- $\mathrm{T}_{\mathrm{C}}$ phase forms on the surface of the high- $\mathrm{T}_{\mathrm{C}}$ phase one. In this case a sufficiently thin layer of the low- $\mathrm{T}_{\mathrm{C}}$ phase can play a role in the weak link.

Although increasing $\mathrm{Li}$ concentration to 0.3 degraded the granular quality of the sample meanwhile; it raised $\mathrm{T}_{\mathrm{C}}$ to $130 \mathrm{~K}$. This could mainly due to the strong link and increasing the contact areas between the grains during the sintering process in other words decrease of porosity [17]. Moreover a broadening transition is noted and this 


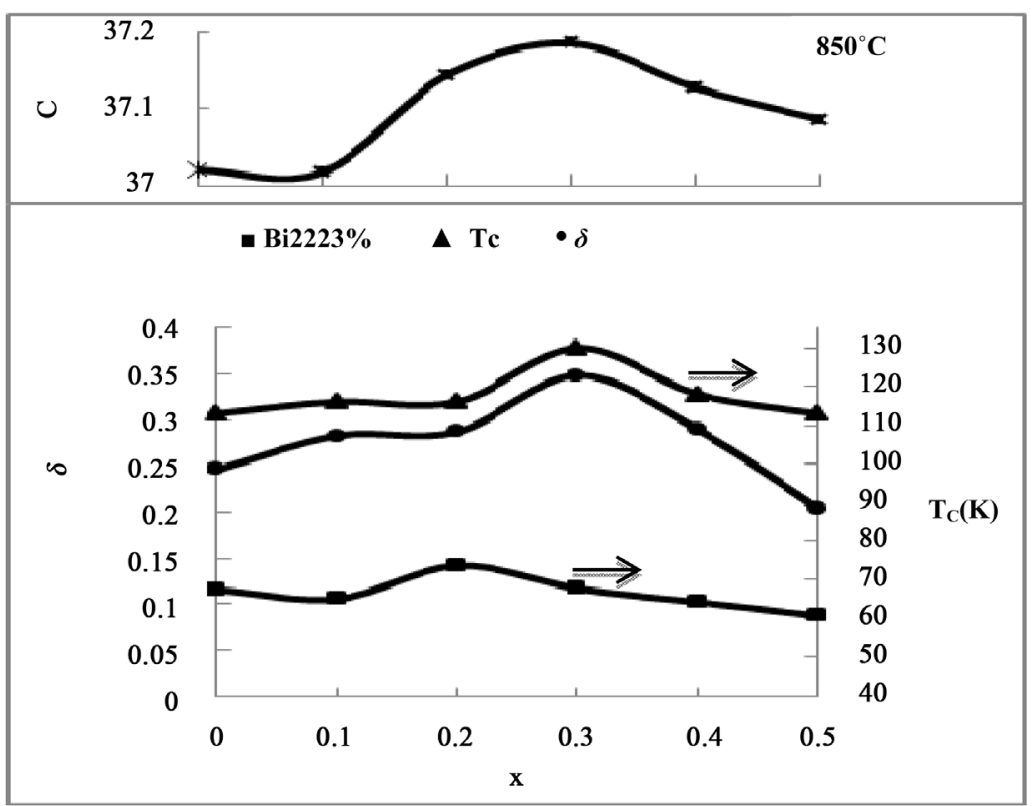

Figure 4. Volume fraction, c parameter, $\delta$ and $\mathrm{T}_{\mathrm{C}}$ with different concentrations for samples of third group.

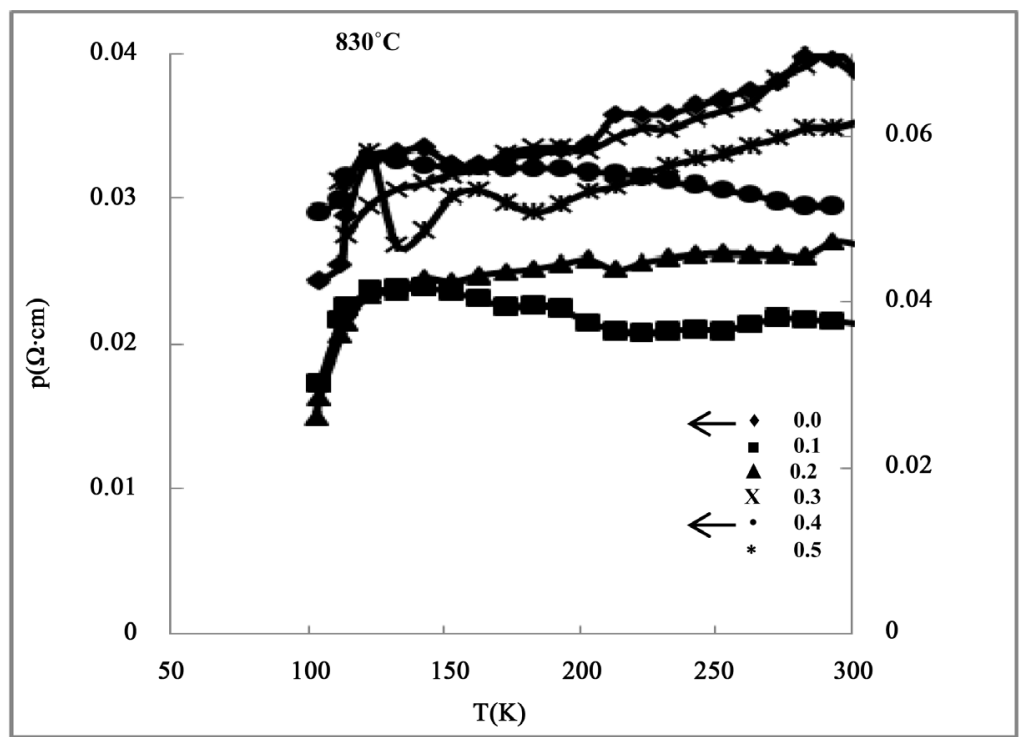

Figure 5. Temperature dependence of resistivity for $\mathrm{Bi}_{2-x} \mathrm{Li}_{\mathrm{X}} \mathrm{Pb}_{0.3} \mathrm{Sr}_{2} \mathrm{Ca}_{2} \mathrm{Cu}_{3} \mathrm{O}_{10+\delta}$ with $0 \leq \mathrm{x} \leq 0.5$ first group.

may be due to the presence of impurities or non-superconducting regions or multi superconducting phases in the sample. The most probable reason may be the existence of multi superconducting phases.

Increasing the $\mathrm{Li}$ concentration to $\mathrm{x}=0.4$ and 0.5 results in a substantial degradation of the $(\mathrm{Bi}, \mathrm{Pb})-2223$ phase and decreases the critical temperature. Another feature was noticed a sharp drop at the transition temperature which is attributed to the transition within the grains and the presence of low- $\mathrm{T}_{\mathrm{C}}$ phase $\mathrm{Bi}-2212$.

This results suggest the increasing amounts of Li content in $\mathrm{Bi}-2223$ phase stabilizes and promotes the growth of the $\mathrm{Bi}-2212$ phase at the expense of $\mathrm{Bi}-2223$. This result in good agreement with that obtained by Halim et al. [18].

It should be emphasized that, in most of hole-doped cuprates (but not in all), $\mathrm{T}_{\mathrm{C}}$ as a function of doping has bell-like shape which is common behavior in mono-or bilayer cuprates. Thus, the different doping regions of the 


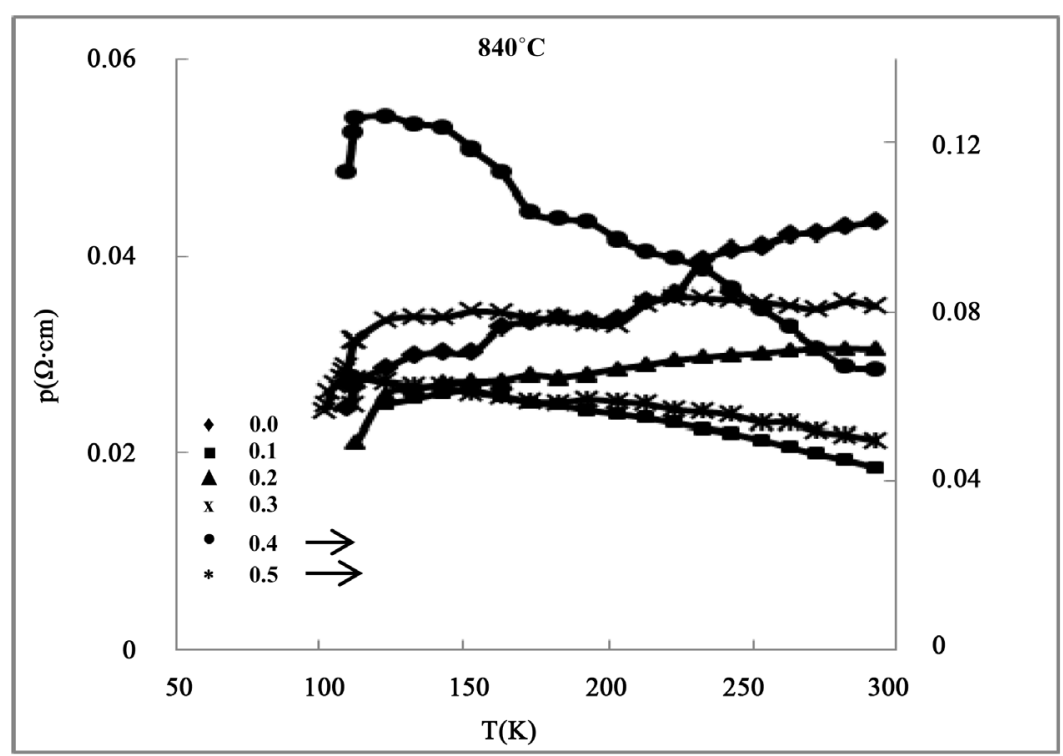

Figure 6. Temperature dependence of resistivity for $\mathrm{Bi}_{2-\mathrm{x}} \mathrm{Li}_{\mathrm{x}} \mathrm{Pb}_{0.3} \mathrm{Sr}_{2} \mathrm{Ca}_{2} \mathrm{Cu}_{3} \mathrm{O}_{10+\delta}$ with $0 \leq \mathrm{x} \leq 0.5$ second group.

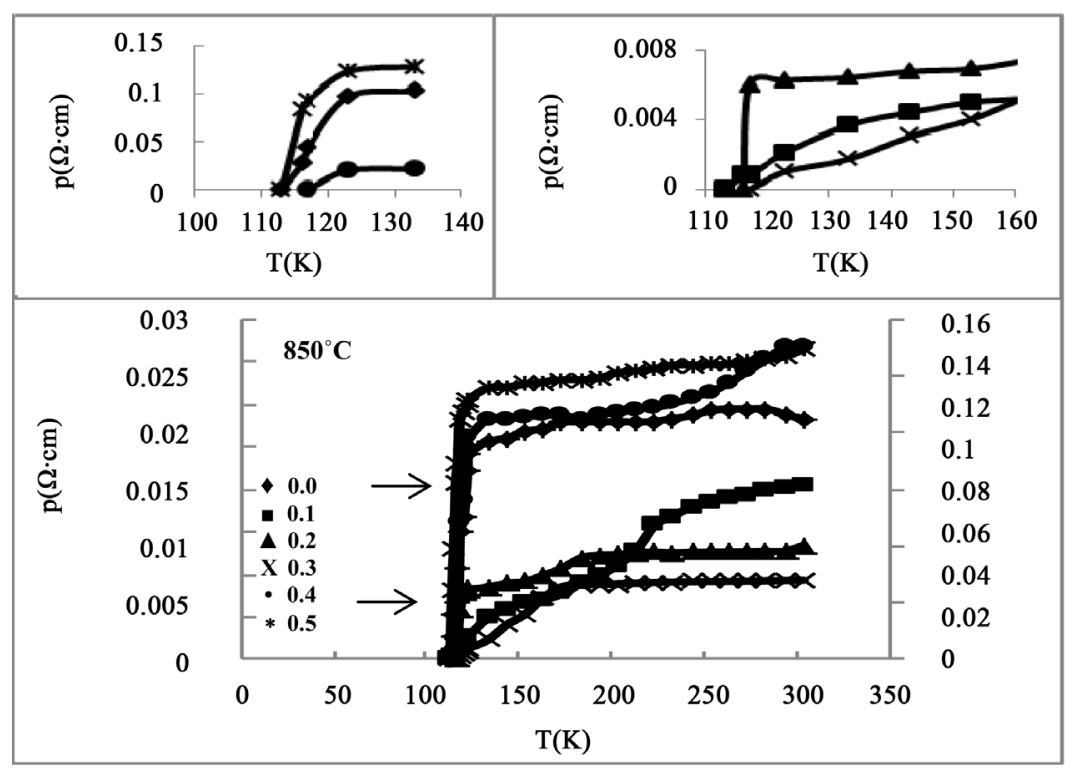

Figure 7. Temperature dependence of resistivity for $\mathrm{Bi}_{2-\mathrm{x}} \mathrm{Li}_{\mathrm{x}} \mathrm{Pb}_{0.3} \mathrm{Sr}_{2} \mathrm{Ca}_{2} \mathrm{Cu}_{3} \mathrm{O}_{10+\delta}$ with $0 \leq \mathrm{x} \leq 0.5$ third group. The two small figures above are partial enlarged details of the large version below.

superconducting phase may be chosen such as the underdoped, optimally doped and overdoped regions [19] [20].

According to the above results the relation between $\mathrm{T}_{\mathrm{C}}$ and $\mathrm{Li}$ concentration is almost parabolic as given in Figure 8, and can be explained based on the parabolic dependence between $T_{C}$ and the number of holes per $\mathrm{CuO}_{2}$ layer [21]. Since the samples with the majority of Bi-2223 are in the underdoped state, their superconducting parameters tend to optimal values with increasing $\mathrm{Li}$ concentration. Highest $\mathrm{T}_{\mathrm{C}}$ was determined at 0.3 which confirm that the sample is in optimal doping regime while decrease of $T_{C}$ beyond this concentration seems to be due to the shift of this sample towards the over-doped region. However, increasing Li concentration, decreases the $T_{C}$ but does not inhibit the formation of (BiPb)-2223 phase. These observations are confirmed by XRD analysis.

$\mathrm{Bi} 2223$ is very sensitive to oxygen; it has been found that increasing the time of sintering causes a decrease of 

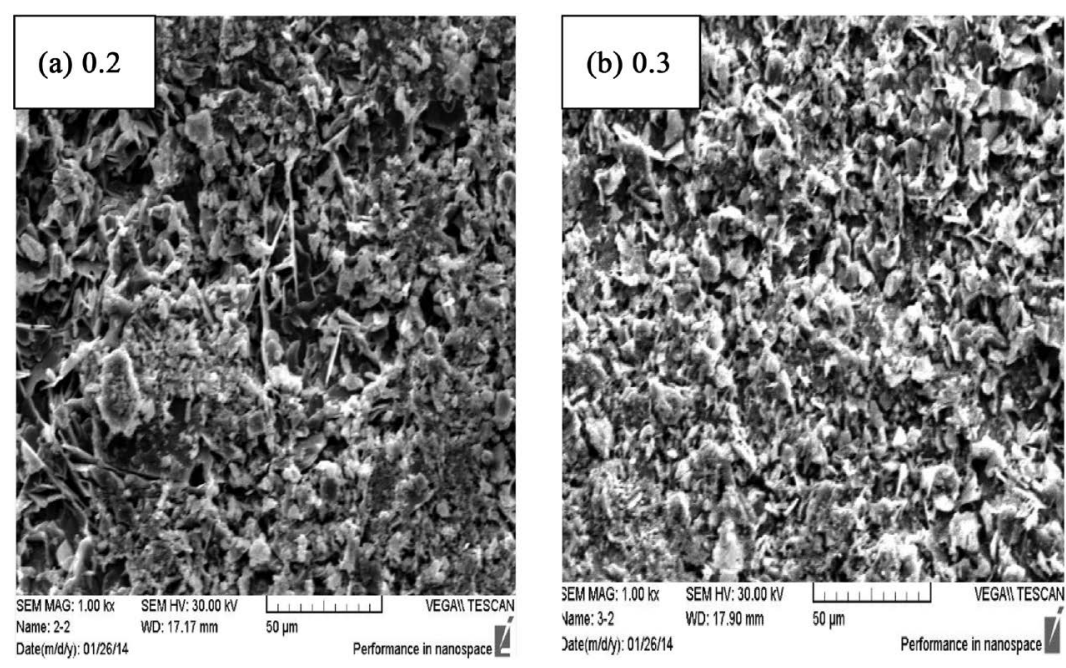

Figure 8. SEM for second group samples.

the oxygen content [22]. According to McKernan et al. diffusion of the oxygen is more rapid at high temperature [23]. From all the analysis results given in Figure 4 and Table 2, it is seen that synthesis sample sintering at higher temperature within short time by multiple pressing and sintering process (third group) increases the oxygen content. This agree with [24], he observed that the values of $\delta$ increased by multi-step technique. Higher value of $\delta$ determined at Li concentration 0.3 , and then reduced for further increasing of substitution. It is well known that Li-doping lowers the melting temperature of this phase so the decrease in oxygen content would be expected [25].

It can be easily inferred that both the $\delta$ and $\mathrm{T}_{\mathrm{C}}$ increased, with increasing $\mathrm{x}$ to 0.2 and 0.3 , then reduced for further increasing of substitution similar behavior of oxygen content with the transition temperature for for $\mathrm{Bi}_{1.6} \mathrm{~Pb}_{0.4} \mathrm{Sr}_{2} \mathrm{Ca}_{3} \mathrm{Cu}_{4} \mathrm{O}_{10+\delta}$ system was indicated by Zhao et al. [26]. This apparently it is due to Bi replacement by $\mathrm{Li}$ ion, so the presence of excess oxygen atoms in the $\mathrm{CuO}_{2}$ layers will create more holes in the perovskite layers, the creation of holes will shorten the $\mathrm{Cu}-\mathrm{O}_{2}$ bond length and this leads to an improvement of the $\mathrm{T}_{\mathrm{C}}[8]$ [27].

Whereas, substitution by $\mathrm{Pb}$ decreases the average valance of $\mathrm{Cu}$ and thereby the average $\mathrm{CuO}_{2}$-plane hole concentration in $\mathrm{BiPb}-2223$. Therefore the reduction of $\mathrm{T}_{\mathrm{C}}$ is argue to out of plane substitution of $\mathrm{Pb}$ for $\mathrm{Bi}$ where show a longer wavelength of structural modulation [28].

Thereafter increasing Li concentration beyond 0.3, caused decrease both $\delta$ and $\mathrm{T}_{\mathrm{C}}$. This effect related to the charge ordering phenomenon, probably induced by $\mathrm{Li}$ and $\mathrm{Pb}$ as a pair breaker, may be a accompanied by changes in oxygen content or oxygen order effects which is decreases the number of holes in the lattice [29] results suggest that as the hole concentration of the compound increases above a critical value, the superconductor is suppressed.

From the viewpoint it is obviously each of $\mathrm{T}_{\mathrm{C}}, \delta$ and c parameter have harmonious behavior with doping concentration.

Surface morphology of the samples showed a noticeable change observed of the grain size, shape and distribution on the surface. This indicates the influence of sintering temperature and varying Li concentration on the morphology of the samples.

Figure 8 illustrates the SEM for $\mathrm{x}=0.2$, and 0.3 samples sintered at $840^{\circ} \mathrm{C}$ (second group), a formation of very small crystal regions with no preferred orientation with in the limit of SEM, was observed. These suggest that grain growth of the superconducting phase is insufficient within this range of temperatures. Increasing the sintering temperature up to $850^{\circ} \mathrm{C}$ (third group) yielded larger grains (larger crystallinities) as shown in Figure 9 for the samples at different doping concentration of $\operatorname{Li}(x=0,0.1,0.2,0.3,0.4$ and 0.5$)$. Samples with larger grains had superconductor behavior with higher $\mathrm{T}_{\mathrm{C}}$ this effectively increases the contact areas and leads to smaller current density under the same applied current.

The SEM image of undoped and 0.1 Li concentration specimens show more voids and small size grains with thin flake like structures, indicating poor formation of the superconducting phase. While increasing Li concentration up to 0.3 yields larger grains with formation of needle like. In addition a plate like grains which are the 
Table 2. The sintering temperature, oxygen content and critical temperature with concentration for all groups.

\begin{tabular}{cccc}
\hline $\mathrm{x}$ & Sintering temp. $\left({ }^{\circ} \mathrm{C}\right)$ & $\delta$ & $\mathrm{T}_{\mathrm{C}}(\mathrm{K})$ \\
\hline 0.0 & First series & $<.1836$ & $<77$ \\
& Second series & $<77$ & 113 \\
& Third series & 0.2021 & $<77$ \\
0.1 & First series & 0.2465 & $<77$ \\
& Second series & 0.2167 & 116 \\
0.2 & Third series & 0.2187 & $<77$ \\
& First series & $<.2835$ & $<77$ \\
0.3 & Second series & 0.2195 & $<16$ \\
& Third series & First series & $<77$ \\
& Second series & 0.2201 & $<77$ \\
0.4 & Third series & 0.2876 & 130 \\
& First series & 0.2211 & $<77$ \\
& Second series & 0.2264 & $<77$ \\
& Third series & 0.34908 & 118 \\
& First series & 0.2199 & $<77$
\end{tabular}
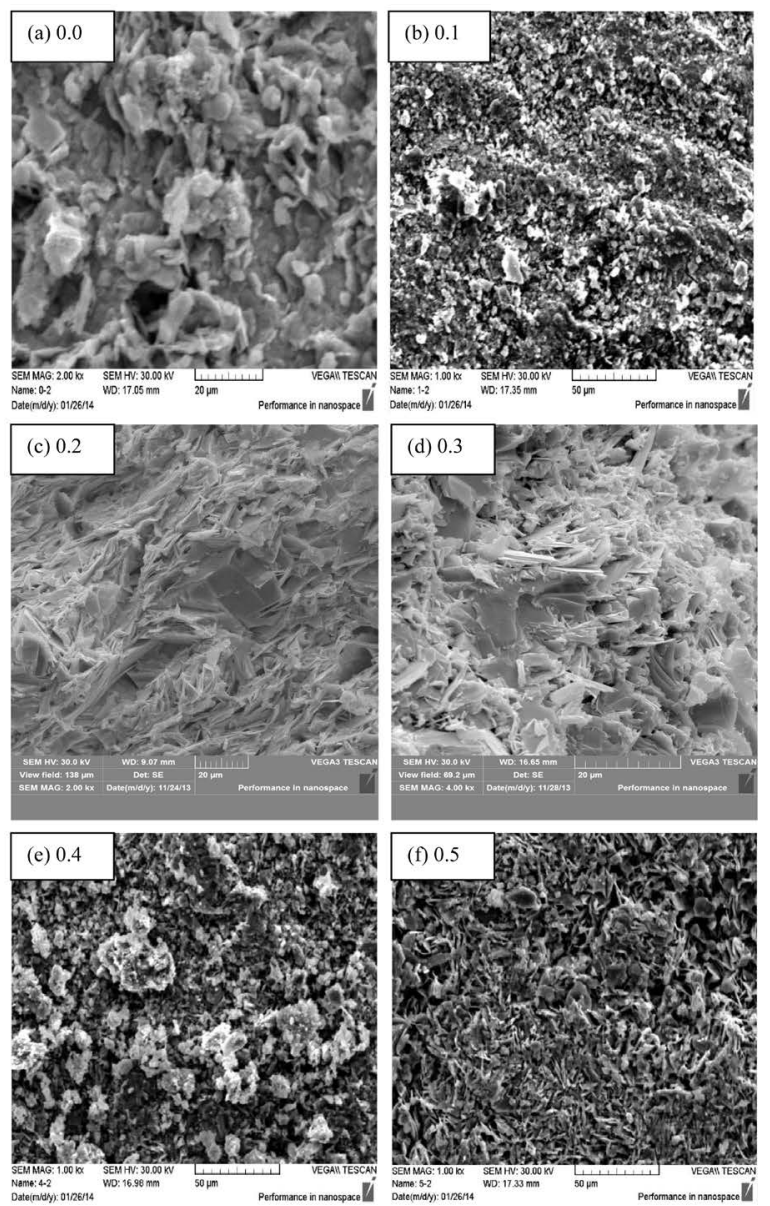

Figure 9. SEM for third group samples. 
typical grain structure of $(\mathrm{Bi}, \mathrm{Pb})-2223$ had been formed, similar results were pointed out by Takano et al. [3].

A drastic change were found in the grain morphology grain size, shape and grain orientation gradually changed and reduced with increasing the amount of Li substitution in the main matrix. As can be seen from Figure 9(e) and Figure 9(b) thin grains seems to have decomposed into small grains and have more pores for samples with $\mathrm{x}=0.4$, and $\mathrm{x}=0.5$.

All the XRD, SEM and resistivity, studies implied that higher amount of Li up to an optimum concentration 0.3 promotes the formation of 2223 phase to achieve higher $T_{C}$ values. This may be attributed to the capability of Li to facilitate oxygenation of the samples and could be responsible for nucleating more of the 2223 grains with the desired stoichiometry.

\section{Conclusions}

Sintering temperature is considered to be a critical value for the high- $\mathrm{T}_{\mathrm{C}}$ phase formation and the optimum sintering temperature appears to be close to the partial melting point (just below the melting temperature). Moreover, it has been observed that synthesis Bi-2223 within short sintering time by multiple pressing and sintering process which lead to larger growth of grain size and thus yield stronger coupling at the grain boundaries. It did improve the superconductivity properties and growth the high- $\mathrm{T}_{\mathrm{C}}$ phase.

Substitution of $\mathrm{Li}$ and $\mathrm{Pb}$ altered the electronic structure of BSCCO system and simultaneously influenced the superconducting $T_{C}$. However, samples with $\mathrm{Li}$ substitution of 0.3 exhibited maximum values of $\mathrm{T}_{\mathrm{C}}, 130 \mathrm{~K}$.

Oxygen incorporation into sample allows an uptake of the optimal oxygen content into matrix, which leads to the prominent enhancement of $\mathrm{T}_{\mathrm{C}}$ and the high- $\mathrm{T}_{\mathrm{C}} 2223$ phase formation.

Different behavior of the superconducting parameters attributed to the effect of doping with different concentration and oxygen content based on the parabolic dependence between $\mathrm{T}_{\mathrm{C}}$ and the number of holes per $\mathrm{CuO}_{2}$ layer. Therefore, multi-step technique combining with Li doping, appears to be an efficient way to bring the usually under-doped superconductor to its optimal $\mathrm{T}_{\mathrm{C}}$.

\section{References}

[1] Saleh, S.A. (2006) Studies on Sintering Effect on the Structural and Transport Properties of (2223) Phase. Physica C, 444, 40-44. http://dx.doi.org/10.1016/j.physc.2006.05.101

[2] Muhammad, A.R. and Maqsood, A. (2010) Synthesis and Thermo Physical Characterization of Bismuth Based High- $\mathrm{T}_{\mathrm{c}}$ Superconductors, Superconductor.

http://www.intechopen.com/books/superconductor/synthesis-and-thermophysical-characterization-of-bismuth-based-hi gh-tc-superconductors

[3] Takano, M., Takada, J., Oda, K., Kitaguchi, H., Miura, Y., Ikeda, Y., Tomii, Y. and Mazaki, H. (1988) High-T Chase Promoted and Stabilized in the Bi, Pb-Sr-Ca-Cu-O System. Japanese Journal of Applied Physics, 27, L1041-L1043. http://dx.doi.org/10.1143/JJAP.27.L1041

[4] Agostinelli, E., Bohandy, J., Green, W.J., Bargeron, C.B., Phillips, T.E., Kim, B.F., Adrian, F.J. and Moorjani, K. (1989) Stabilization of the $108 \mathrm{~K}$ Superconducting Phase in the $\mathrm{Bi}_{0.7} \mathrm{~Pb}_{0.3} \mathrm{SrCaCu}_{1.8} \mathrm{O}_{\mathrm{y}}$ System. Journal of Superconductivity, 2, 3361-367. http://dx.doi.org/10.1007/BF00618523

[5] Dey, T.K. (1998) Effect of Sintering Duration on the Thermal Conductivity of (Bi, Pb)-2223 Superconducting Pellets between 10 and 150 K. Journal of Superconductivity, 11, 279-284. http://dx.doi.org/10.1023/A:1022692119723

[6] Fernando, P.R. and Pathmanathan, N. (2006) Fabrication and Characterization of $\mathrm{Bi}_{1.6} \mathrm{~Pb}_{0.4} \mathrm{Sr}_{2} \mathrm{Ca}_{2} \mathrm{Cu}_{3} \mathrm{O}_{\mathrm{y}}$ Superconductors Prepared by Solid State Reaction Technique. Sri Lankan Journal of Physics, 7, 7-13.

[7] Bilgili, O., Selamet, Y. and Kocabas, K. (2008) Effects of Li Substitution in Bi-2223 Superconductors. Journal of Superconductivity and Novel Magnetism, 21, 439-449. http://dx.doi.org/10.1007/s10948-008-0374-4

[8] Abbas, M.M., Abass, L.K. and Salman, U. (2012) Influences of Sintering Time on the $\mathrm{T}_{\mathrm{C}}$ of $\mathrm{Bi}_{2-\mathrm{x}} \mathrm{Cu}_{\mathrm{x}} \mathrm{Pb}_{0.3} \mathrm{Sr}_{2} \mathrm{Ca}_{2} \mathrm{Cu}_{3} \mathrm{O}_{10+\Delta}$ High Temperature Superconductors. Energy Procedia, 18, 215-224. http://dx.doi.org/10.1016/j.egypro.2012.05.033

[9] Koyama, S., Endo, U. and Kawai, T. (1988) Preparation of Single $110 \mathrm{~K}$ Phase of the Bi-Pb-Sr-Ca-Cu-O Superconductor. Japanese Journal of Applied Physics, 27, L1861-L1863. http://dx.doi.org/10.1143/JJAP.27.L1861

[10] Kocabas, K. (1998) Effect of Sintering Time on Sb Added BiPbSrCaCuO Superconducting Ceramics. Turkish Journal of Physics, 22, 437-440.

[11] Gundakaram, R., Chang, S.C., Liu, R.S., Woodall, L. and Gerards, M. (2001) Studies into the Phase Transformation of Bi-2223 Precursor Powders Using X-Ray Diffraction and SQUID Susceptibility Measurements. IEEE Transactions on Applied Superconductivity, 11, 3182-3185. http://dx.doi.org/10.1109/77.919739 
[12] Mohammed, N.H., Awad, R., Abou-Aly, A.I., Ibrahim, I.H. and Hassan, M.S. (2012) Optimizing the Preparation Conditions of Bi-2223 Superconducting Phase Using $\mathrm{PbO}$ and $\mathrm{PbO}_{2}$. Journal of Materials Science and Applications, 3, 224-233. http://dx.doi.org/10.4236/msa.2012.34033

[13] Azhan, H., Azman, K. and Yusainee, S.Y.S. (2009) The Role of Antimony (Sb) Addition on BSCCO Superconductor. Solid State Science and Technology, 17, 215-221.

[14] lkeda, Y., Takno, M., Hiroi, Z., Oda, K., Kitaguchi, H., Takada, J., Miura, Y., Takada, Y., Yamamoto, O. and Mazaki, H. (1988) The High- $T_{c}$ with a New Modulation Mode in the Bi,Pb-Sr-Ca-Cu-O System. Japanese Journal of Applied Physics, 27, L2067-L2070. http://dx.doi.org/10.1143/JJAP.27.L2067

[15] Bolat, S., Yanmaz, E. and Comert, H. (2000) Properties of Ag-Doped $\mathrm{Bi}_{1.6} \mathrm{~Pb}_{0.4} \mathrm{Sr}_{2} \mathrm{Ca}_{3} \mathrm{Cu}_{4-\mathrm{x}} \mathrm{Ag}_{\mathrm{x}} \mathrm{O}_{\mathrm{y}}$ (2234) Oxides Prepared by S.S.R. Method. Turkish Journal of Physics, 24, 129-135.

[16] Iqbal, M.J. and Mehmood, R. (2009) Improvement in High- $T_{c}$ Phase Formation in (Thallium-Antimony) Doped Bismuth-Based Superconducting Materials. Journal of Alloys and Compounds, 477, 386-390. http://dx.doi.org/10.1016/j.jallcom.2008.10.006

[17] Heh, T.S., Chen, J.R. and Tseng, T.Y. (1990) Preparation of $\mathrm{Bi}_{0.7} \mathrm{~Pb}_{0.3} \mathrm{SrCaCu}_{1.8} \mathrm{O}_{\mathrm{y}}$ High- $T_{c}$ Superconductor by the Citrate Method. Japanese Journal of Applied Physics, 29, 4652-4655.

[18] Halim, S.A., Ravandi, S.S.H., Adam, M.I., Chen, S.K., Lim, K.P., Baqiah, H., Faisal, M.A.M. and Kamarulzaman, M.M. (2010) Influence of Addition of $\mathrm{Eu}_{2} \mathrm{O}_{3}$ Nanoparticle on the Structural and Superconducting Properties of $\left(\mathrm{Bi}_{1.6} \mathrm{~Pb}_{0.4}\right) \mathrm{Sr}_{2} \mathrm{Ca}_{2} \mathrm{Cu}_{3} \mathrm{O}_{10}$ Ceramics. Solid State Science and Technology, 18, 266-271.

[19] Fujii, T., Terasaki, I., Watanabe, T. and Matsuda, A. (2002) Doping Dependence of Anisotropic Resistivities in Trilayered Superconductor $\mathrm{Bi}_{2} \mathrm{Sr}_{2} \mathrm{Ca}_{2} \mathrm{Cu}_{3} \mathrm{O}_{10+\delta}$ (Bi-2223). Physical Review B, 66, Article ID: 024507.

[20] Parinov, I.A. (2012) Microstructure and Properties of High-Temperature Superconductors. Springer-Verlag Berlin Heidelberg, Berlin. http://dx.doi.org/10.1007/978-3-642-34441-1

[21] Mihalache, V., Aldica, G. and Miu, D. (2006) Modification of the Superconducting Parameters of Bi-Sr-Ca-Cu-O by Iodine Intercalation. Journal of Optoelectronics and Advanced Materials, 8, 1287-1291.

[22] Hermiz, G. (2001) Thermal Analysis and Phase Transformation of HTSC of $\left(\mathrm{Bi}_{1-\mathrm{x}} \mathrm{Pb}_{\mathrm{x}}\right)_{2}\left(\mathrm{Sr}_{1-\mathrm{y}} \mathrm{Ba}_{\mathrm{y}}\right)_{2} \mathrm{Ca}_{2} \mathrm{Cu}_{3} \mathrm{O}_{10} \mathrm{Com}_{-}$ pound. Ph.D. Thesis, Baghdad University, Baghdad.

[23] McKernan, S. and Zettl, A. (1993) High-Temperature Resistivity and Oxygen Diffusion in $\mathrm{Bi}_{2} \mathrm{Sr}_{2} \mathrm{CaCuO}_{\mathrm{x}}$. Physics C, 209, 585-590. http://dx.doi.org/10.1016/0921-4534(93)90579-F

[24] Al-Taie, S. (2004) Investigation of Preparation Process and Composition of the Superconductor $\mathrm{Bi}_{1.6} \mathrm{~Pb}_{0.4} \mathrm{Sr}_{2+\mathrm{x}} \mathrm{Ca}_{2+\mathrm{y}} \mathrm{Cu}_{3}$ $\mathrm{O}_{10+\delta}$. Master's Thesis, Baghdad University, Baghdad.

[25] Mua, N.T., Sundaresan, A., Man, N.K. and Dung, D. (2014) Influence of Preparation Conditions on Superconducting Properties of Bi-2223 Thin Films. Bulletin of Materials Science, 37, 19-25. http://dx.doi.org/10.1007/s12034-014-0627-8

[26] Zhao, J., Wu, M., Abdul-Razzaq, W. and Seehra, M.S. (1990) Interrelationship between the Transition Temperatures of the (2223) and (2212) Phases of Bi-Based Superconductors. Physica C, 165, 135-138. http://dx.doi.org/10.1016/0921-4534(90)90156-9

[27] Khaled, J., Komatsu, T. and Sato, R. (1997) Formation and Thermal Stability of High- $T_{c}$ Phase in Te-Doped Bi-Based Superconducting Glass-Ceramics. Journal of the Ceramic Society of Japan, 105, 279-283. http://dx.doi.org/10.2109/jcersj.105.279

[28] Maeda, H. and Togano, K. (1996) Bismuth-Based High Temperature Superconductors. Marcel Dekker, Inc., New York.

[29] Shatkovskis, E., Dapkus, L. and Pyragas, V. (2000) The Metastable Superior Phases in Bi-2212 Perovskite-Like HighTemperature Superconductor. Defects and Surface-Induced Effects in Advanced Perovskites: NATO Science Series, 77, 161-166. http://dx.doi.org/10.1007/978-94-011-4030-0_17 